\title{
AC 2008-51: LABORATORY EXPERIMENT IN THE FREE CONVECTION OF A VERTICAL HEATED CONSTANT TEMPERATURE PLATE USING LABVIEW
}

\section{Erik Bardy, Grove City College}

ERIK R. BARDY currently serves as Assistant Professor of Mechanical Engineering at Grove City College. His research interests include composite insulation design, orthopedic biomechanics and thermal regulation of the human body.

\section{Erik Anderson, Grove City College}

ERIK J. ANDERSON currently serves as Assistant Professor of Mechanical Engineering at Grove City College. His research interests include biofluid dynamics and biomimetic robotics with applications to marine vehicles. 


\title{
Laboratory Experiment in the Free Convection of a Vertical Heated Constant Temperature Plate using LabVIEW
}

\begin{abstract}
The measurement and automation programming language LabVIEW features data acquisition (DAQ) toolboxes that interface with plug and play National Instruments (NI) DAQ hardware. Code can be compiled and packaged as executable files that can then be loaded on multiple PCs without additional licensing. The authors have developed a student laboratory exercise that uses LabVIEW to collect temperature data on and near a vertical plate (Polycarbonate) heated on one side by water $\left(\mathrm{T}=\sim 100^{\circ} \mathrm{C}\right)$. Heat is conducted through the plate and then to the air by natural convection. Thermocouples connected to a NI-DAQ PC interface card measured temperatures on and near the plate at six vertical locations, generating temperature profiles within the thermal boundary layer. Students monitored and recorded temperatures on-demand using a LabVIEW program run from an executable file on the host PC. The objective of the lab is to introduce students to experimental and analytical methods of free convective heat transfer analysis including: the application of similarity solutions, experimental measurement, and the analytical and experimental determination of the convective heat transfer coefficient. A description of the experiment and the implementation of LabVIEW are presented along with sample experimental data and results of a student survey.
\end{abstract}

\section{Introduction}

Experimental demonstrations of heat transfer are an important part of the undergraduate Mechanical Engineering curriculum. Students at Grove City College entering their junior year have little experience with advanced data acquisition systems and comparing the data they collect to theories learned in class. Mechanical Engineering students take a laboratory course (1 credit, MECE 352) in the spring term of the junior year in thermal/fluid sciences. Although educational laboratory equipment and experiments built by companies such as P.A. Hilton and Turbine Technologies LTD are great additions to this course they can be very expensive. Building heat transfer experiments in-house can result in considerable savings. A number of institutions have built experiments for various heat transfer experiments. ${ }^{[1-6]}$ In some cases students have built heat transfer experiments as part of a design project and then used the experiment in a thermal fluids laboratory course. ${ }^{[7,8]}$.

We have developed an experiment in free convection for MECE 352 adapted from one used in the Department of Mechanical and Aerospace Engineering at The State University of New York at Buffalo (SUNY Buffalo) (with permission). In the experiment, students take direct temperature readings from a vertical heated plate using thermocouples and a LabVIEW DAQ interface. The convective heat transfer coefficient can be calculated from the temperature profile near the vertical plate and compared to analytically determined values. In addition, students are exposed to similarity solutions used to solve the momentum and energy equations that govern the fluid flow and heat transfer within the velocity and thermal boundary layers. 


\section{Experimental Apparatus}

The experiment consists of an aluminum water tank (11.75" x 5.5" x 22") with one wall constructed out of 0.5 " clear plastic (Lexan) and surrounded by a Plexiglas shield (Figure 1). A hot water tank heater $(2000 \mathrm{~W})$ is inserted through the bottom of the tank to heat the water. The temperature of the water in the tank is maintained at near boiling temperature $\left(\sim 95^{\circ} \mathrm{C}\right)$ with a temperature and process controller (CNi3243, National Instruments). Six thin gage, noninsulated tip thermocouples (type K, Omega Corp., precision fine wire, AWG gage 30, diameter $=0.25 \mathrm{~mm}, 0.01 \mathrm{in}$, length $=916.4 \mathrm{~mm}, 36 \mathrm{in}$ ) are inserted halfway through the thickness of the clear plastic in six locations to measure wall temperature at specific locations as shown in Figure 1. One thermocouple (TC7, i.e. thermocouple number 7) is placed at a location far from the heated plate to measure ambient temperature. Another (TC8) is mounted on a depth gage that is free to slide parallel to the plate. Thus, it can be positioned to measure temperature throughout the thermal boundary layer. Students position TC8 at different depths over the six implanted thermocouple locations (TC1-6) where they monitor and log temperature data using a LabVIEW interface and a data acquisition system (NI USB-9162, National Instruments). The LabVIEW interface is run from an executable file and is explained in the following section.
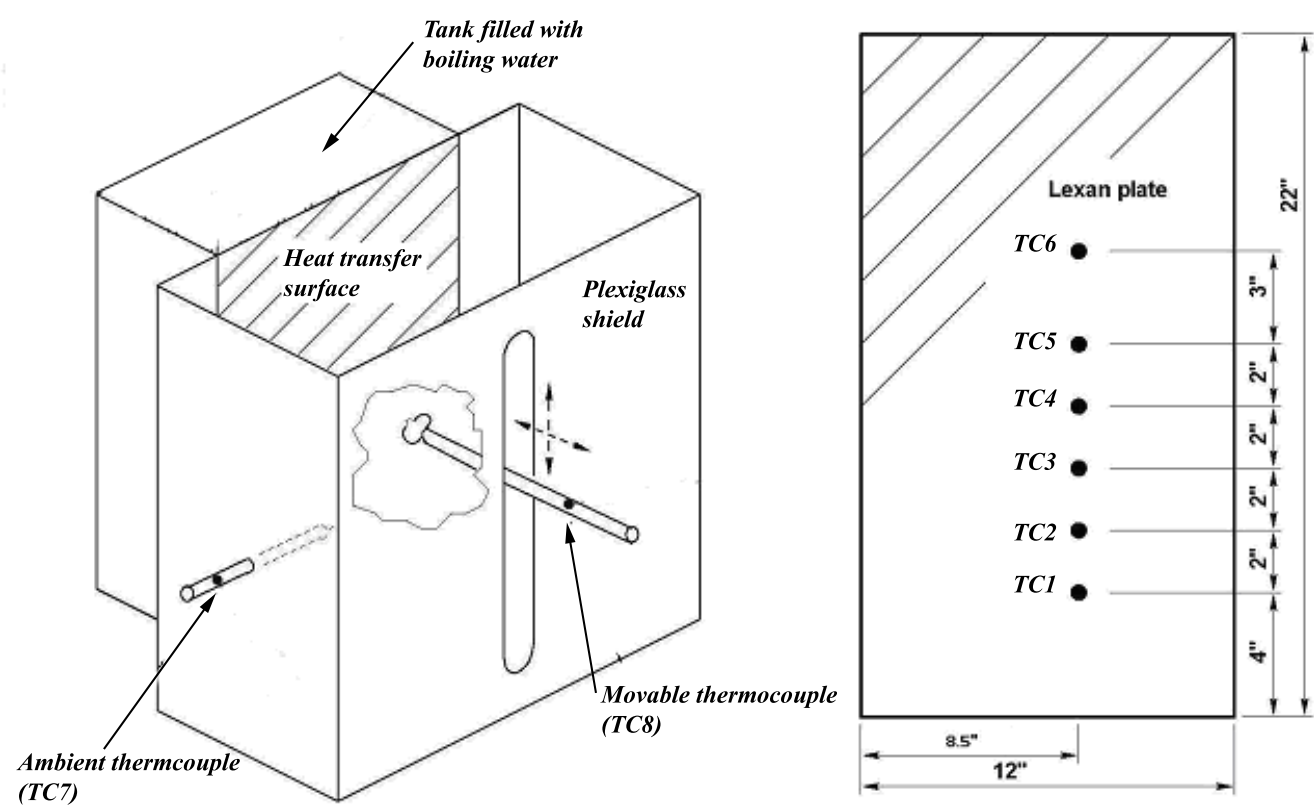

Figure 1 Schematic of the experimental apparatus (left) and front view of the heated Lexan plate with the locations of the six implanted thermocouples (right).

*Diagram reproduced and modified with permission from SUNY Buffalo. 


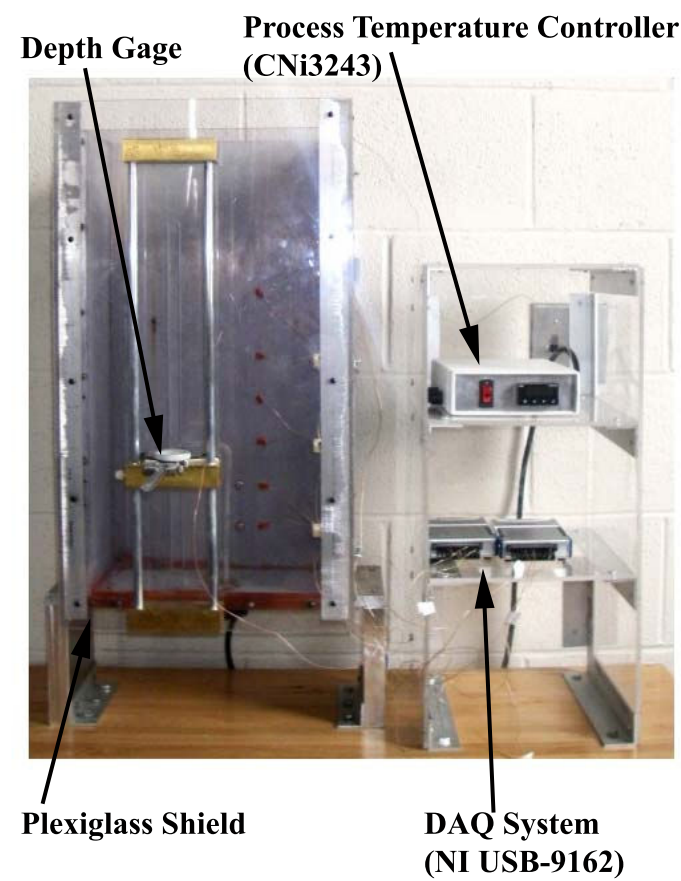

Figure 2 Photograph of experimental set-up.

\section{LabVIEW Executable Feature}

LabVIEW (version 8.0, National Instruments) is a graphical programming language with built-in capabilities to facilitate data acquisition (DAQ) and instrument control. In LabVIEW, the programmer creates the front panels of "virtual instruments," such as an oscilloscope or the control panel for a nuclear power plant, and then "writes" code that looks like a flowchart. The flowchart determines the functionality of the virtual instrument. The front panel of the thermocouple data acquisition program is shown in Figure 3.

Students move TC 8 to a given position on the experimental apparatus and then hit a button on the front panel to acquire data from all 8 thermocouples and write them to a spreadsheet file along with an optional note. See Table 1 for an example of the program output. "Behind" the front panel, the graphical LabVIEW code mediates the reading of the thermocouples, and the writing of the data to the front panel and the spreadsheet file. It took less than an hour to create the prototype instrument thanks to a LabVIEW feature known as the 'DAQ assistant.' The DAQ assistant is essentially a wizard that asks you what sort of data acquisition you want to do (channels, sample rate and size, probe type, etc.) and then writes the backbone of the code for you. This makes it possible for even the novice LabVIEW user to create virtual instruments for relatively involved data acquisition. In addition, LabVIEW comes with numerous example programs that are useful for getting started on many common applications. The authors will make the source code for the thermocouple experiment available to anyone interested.

Another advantage of LabVIEW for student laboratory experiments is the programmer's ability to transform the virtual instruments into executable files. These can be installed easily on other computers without the need for additional LabVIEW licenses - a savings of about $\$ 1000$ per 
computer. The computers do not need to have LabVIEW installed. Hence, the virtual instrument can be put on any number of laboratory computers. Using USB-based DAQ hardware, students can even install these programs on their own portable computers and run the experiments from their own machines. Not only does the student learn about heat transfer, but they get a taste of interfacing test equipment and a PC.

The LabVIEW feature called 'Application Builder' builds the executable file and installation disk information. When purchasing LabVIEW, one should be aware that the Application Builder does not come standard with all versions of LabVIEW.

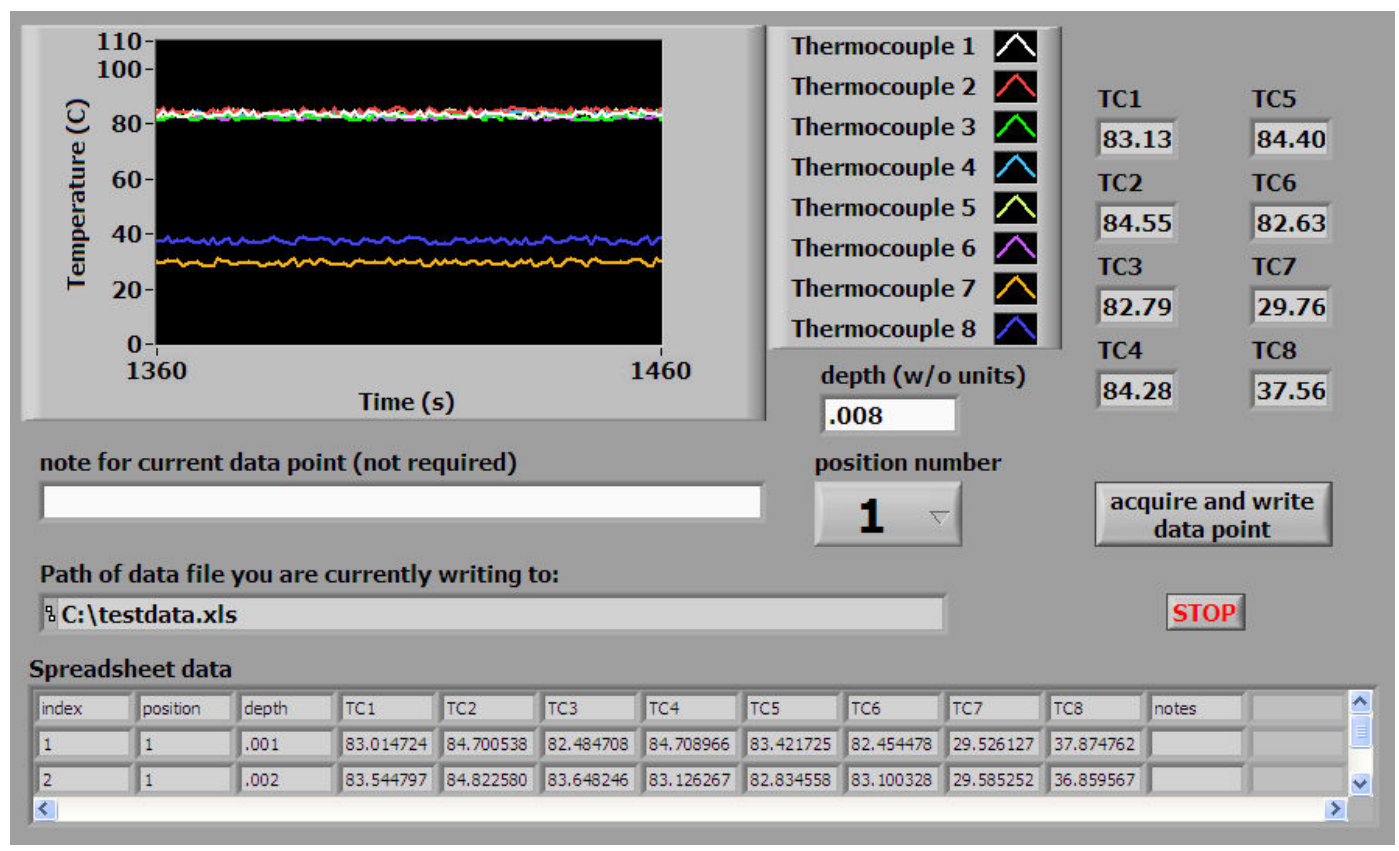

Figure 3 The front panel of the thermocouple data acquisition program.

Table 1 Sample data output of LabVIEW program for station 1 (temperature in ${ }^{\circ} \mathrm{C}$ ).

\begin{tabular}{|c|c|c|c|c|c|c|c|c|c|c|}
\hline index & $\begin{array}{c}\text { Position } \\
\text { number }\end{array}$ & depth & TC1 & TC2 & TC3 & TC4 & TC5 & TC6 & TC7 & TC8 \\
\hline 0 & 1 & 0.000 & 82.1 & 82.2 & 83.9 & 84.3 & 84.2 & 84.7 & 27.8 & 38.5 \\
\hline 1 & 1 & 0.001 & 82.1 & 82.2 & 83.9 & 84.3 & 84.2 & 84.6 & 28.6 & 38.4 \\
\hline 2 & 1 & 0.002 & 82.1 & 82.2 & 83.9 & 84.3 & 84.2 & 84.6 & 29.1 & 37.7 \\
\hline 3 & 1 & 0.003 & 82.1 & 82.2 & 83.9 & 84.3 & 84.2 & 84.6 & 27.7 & 37.9 \\
\hline 4 & 1 & 0.004 & 82.1 & 82.1 & 83.8 & 84.2 & 84.2 & 84.6 & 30.6 & 37.4 \\
\hline 5 & 1 & 0.005 & 82.1 & 82.1 & 83.8 & 84.2 & 84.2 & 84.6 & 27.2 & 36.2 \\
\hline 6 & 1 & 0.006 & 82.0 & 82.1 & 83.8 & 84.2 & 84.2 & 84.6 & 28.6 & 36.6 \\
\hline 7 & 1 & 0.007 & 81.9 & 82.0 & 83.7 & 84.2 & 84.1 & 84.6 & 27.3 & 35.7 \\
\hline 8 & 1 & 0.008 & 82.0 & 82.0 & 83.7 & 84.2 & 84.2 & 84.6 & 27.5 & 36.1 \\
\hline 9 & 1 & 0.009 & 82.0 & 82.1 & 83.7 & 84.2 & 84.2 & 84.6 & 28.4 & 36.0 \\
\hline 10 & 1 & 0.010 & 81.9 & 82.0 & 83.7 & 84.1 & 84.1 & 84.6 & 29.0 & 36.0 \\
\hline$\ldots$ & $\ldots$ & $\ldots$ & $\ldots$ & $\ldots$ & $\ldots$ & $\ldots$ & $\ldots$ & $\ldots$ & $\ldots$ & $\ldots$ \\
\hline
\end{tabular}

* Optional notes are written in a column to the right of the TC8 column.

**All "depth" measurements are in inches. 


\section{Experiment Objectives}

Free convection heat transfer is encountered in many applications (e.g. HVAC, thermodynamic cycles, etc). The vertical heated plate is a classic example. The amount of heat transferred during a free convection process can de determined from knowledge of the convective heat transfer coefficient, which can be empirically and experimentally determined. The objective of this experiment is to:

1. Measure and plot the variation of temperature within the thermal boundary layer at various locations along the length of the plate.

2. Apply the similarity solution to unify all the thermal boundary layer profiles and compare results to similarity plots of various Prandtl numbers (Figure 3).

3. Experimentally determine the convective heat transfer coefficient at six locations on the heated plate and make comparisons to empirically determined values.

\section{Free Convection Heat Transfer of a Vertical Heated Plate $\left(\mathbf{T}_{\mathrm{s}}=\right.$ constant $)$}

Due to buoyancy forces from air heated near the surface of the plate, both a velocity and thermal boundary layer are formed as shown in Figure 4. The upward direction is taken as " $x$ " and the horizontal direction is taken as "y." The momentum and energy equations that govern the motion and the heat transfer are shown in equations (1) through (3). ${ }^{[9]}$

$$
\begin{gathered}
\frac{\partial u}{\partial x}+\frac{\partial v}{\partial y}=0 \\
u \frac{\partial u}{\partial x}+v \frac{\partial u}{\partial y}=g \beta\left(T-T_{\infty}\right)+v \frac{\partial^{2} u}{\partial y^{2}} \\
u \frac{\partial T}{\partial x}+v \frac{\partial T}{\partial y}=\alpha \frac{\partial^{2} T}{\partial y^{2}}
\end{gathered}
$$

Nondimensionalizing equations (1) through (3) yield three non-dimensional parameters; the Reynolds number, the Prandtl number, and the Grashof number. The Grashof number is given by

$$
G r \equiv \frac{g \beta\left(T_{w}-T_{\infty}\right) x^{3}}{v^{2}}
$$

where the thermal expansion coefficient, $\beta$, is evaluated at $\mathrm{T}_{\infty}$ and all other properties are evaluated at $\left(\mathrm{T}_{\mathrm{w}}+\mathrm{T}_{\infty}\right) / 2$. Equations (1) through (3) are subject to the following boundary conditions.

$$
\begin{array}{lll}
\mathrm{u}, \mathrm{v}=0 & \text { at } & \mathrm{y}=0 \\
\mathrm{~T}=\mathrm{T}_{\mathrm{w}} & \text { at } & \mathrm{y}=0 \\
\mathrm{u}, \mathrm{v}=0 & \text { at } & \mathrm{y}=\infty \\
\mathrm{T}=\mathrm{T}_{\infty} & \text { at } & \mathrm{y}=\infty
\end{array}
$$


For constant fluid properties the solution to equations (1) - (3) exists in the form of similarity solutions determined by Ostrach ${ }^{[10]}$. The solution involves transforming variables by introducing the similarity parameter,

$$
\eta \equiv \frac{y}{x}\left(\frac{G r_{x}}{4}\right)^{1 / 4}
$$

This similarity parameter transforms the governing coupled nonlinear partial differential equations into coupled nonlinear ordinary differential equations which reduces the number of independent variables by one. As a result, for a given Prandtl number the temperature profiles at various locations along the length of the plate, $\mathrm{x}$, fall on a single curve when plotted as,

$$
\frac{T-T_{\infty}}{T_{w}-T_{\infty}} \quad \text { vs. } \quad \frac{y}{x}\left(\frac{G r_{x}}{4}\right)^{1 / 4}
$$

The similarity solution for various Prandtl numbers is shown in Figure 4.

\section{Experimental and Empirical Determination of the Heat Transfer Coefficient, $h$}

The heat transfer coefficient, $\mathrm{h}$, is derived from heat transfer characteristics expressed in terms of the Nusselt number, defined as

$$
N u_{x} \equiv \frac{h_{x} x}{k} .
$$

The flow regime for the air flow within the velocity boundary layer is determined from the Rayleigh number, given by,

$$
R a=G r_{x} \operatorname{Pr}
$$

Empirical relationships for the Nusselt number of a vertically heated plate with constant surface temperature have been derived by Churchill and Chu. ${ }^{[11]} \mathrm{A}$ correlation that can be applied for an entire range of Rayleigh numbers is given in equation (10). Another correlation for better accuracy for laminar flow is given by equation (11).

$$
\begin{array}{ll}
\overline{N u}_{L}=\left\{0.825+\frac{0.387 R a_{L}^{1 / 6}}{\left[1+(0.492 / \mathrm{Pr})^{9 / 16}\right]^{8 / 27}}\right\}^{2} & 10^{-1}<R a<10^{12} \\
\overline{N u}_{L}=0.68+\frac{0.67 R a_{L}^{1 / 4}}{\left[1+(0.492 / \mathrm{Pr})^{9 / 16}\right]^{4 / 9}} \quad & R a \leq 10^{9}
\end{array}
$$


From equations (8) through (11) an empirical value for $\mathrm{h}$ can be determined for each location, $\mathrm{x}$, along the surface of the plate.

An experimental value for $\mathrm{h}$ can be obtained according to the boundary condition that the conduction through the surface of the plate is equal to the convective heat loss to the environment shown in equation (12).

$$
-\left.k_{\text {air }} \frac{\partial T}{\partial y}\right|_{y=0}=h_{\exp }\left(T_{w}-T_{\infty}\right)
$$

An approximate temperature gradient, $\partial \mathrm{T} / \partial \mathrm{y}$, at the wall can be calculated from the measured temperature profile.

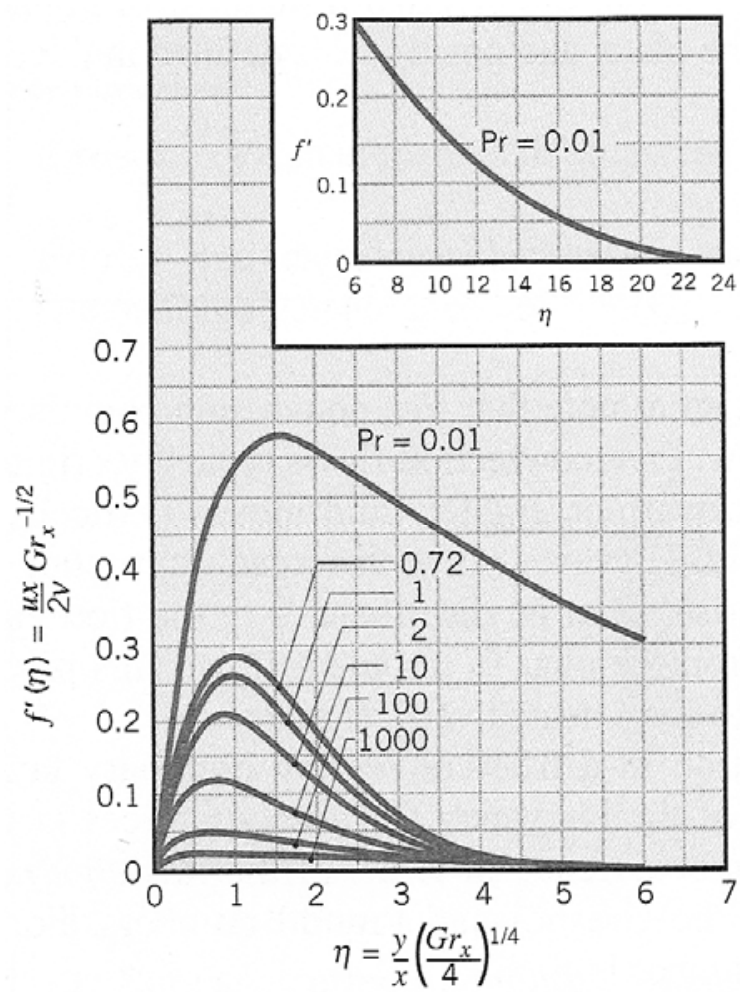

(a)

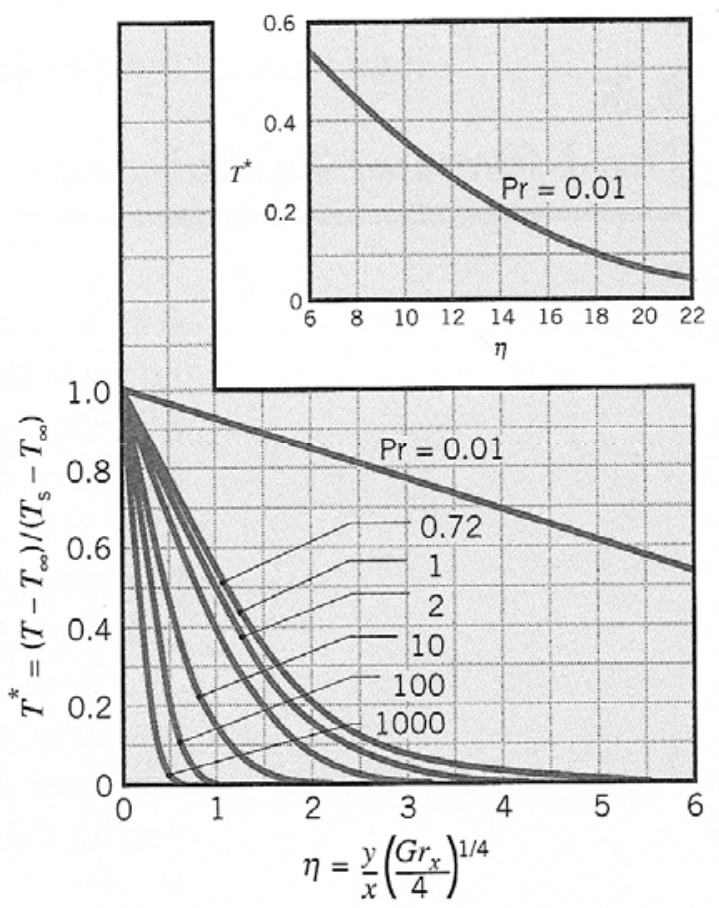

(b)

Figure 4 Laminar, free convection boundary layer conditions on an isothermal vertical surface. (a) Velocity profiles. (b) Temperature profiles ${ }^{[9,10]}$. 


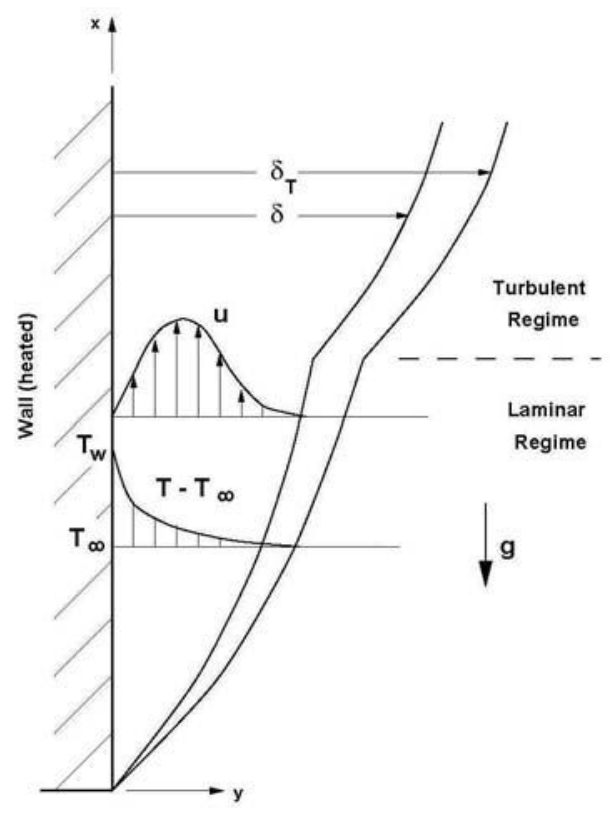

Figure 5 Velocity and temperature profiles in a natural convection boundary layer.

* Diagram reproduced with permission from SUNY Buffalo.

\section{Experimental Procedure}

The temperature of the air (using TC8) is measured as a function of distance away from the plate (y-direction) for each "stop" (corresponding to the positions of TC1-TC6). Temperature profile measurements are made in increments of 0.001 inches over the first 0.01 inches from the wall, 0.01 inch increments from 0.01 to 0.1 , and 0.1 inch increments thereafter. Once it appears that the probe is outside the boundary layer, it is moved to the next location along the plate.

LabVIEW is used to monitor and log the eight thermocouple temperature measurements. Thermocouples $1-6$ (TC1-TC6) measure the plate temperature on the air side for each ydirection stop and are used to check for thermal gradients along the plate surface. Thermocouple 7 (TC7) measures the ambient air temperature. Thermocouple 8 (TC8) can be moved horizontally and vertically to measure the fluid temperature within the boundary layer.

\section{Sample Results and Discussion}

Figure 6 is a plot of the experimentally measured temperature profiles at the six locations along the heated plate including the theoretical laminar profile at location 1 . The temperature at each location for $\mathrm{y}=0$ is approximately $40^{\circ} \mathrm{C}$ (with the exception of location 6 ). This is lower than the wall temperatures measured by TC1-6, which range from approximately $82-85^{\circ} \mathrm{C}$, due to the temperature gradient in the wall. In addition, note that the experimental data shows much cooler air close to the wall than expected from laminar theory. This clear difference between the measured and theoretical profile shape at location 1 was seen for all profiles. This suggests that the flow was not laminar. 
Figure 7 shows the data plotted according to equation (7) compared to the laminar similarity solution for air $(\operatorname{Pr}=0.707)$. Since the measured temperature at $y=0$ (TC8) was lower than that measured by TC1-6, $\mathrm{T}_{\text {wall }}$ was set equal to the temperature measured by TC 8 at $y=0$. All of the measured temperature profiles at the six locations appear to fall along one plot. However, as in Figure 5, the data does not fit laminar theory. This could be attributed to some level of turbulence induced by environmental conditions. Even though the calculated Rayleigh numbers at each location (ranged in order of $10^{6}-10^{8}$ ) indicate laminar flow, it most likely that the entering flow was not completely quiescent. Despite this fact, the experiment clearly illustrates the thermal boundary layer over a heated vertical surface.

Table 2 shows a comparison of the analytically and experimentally determined convection heat transfer coefficients using equations (8) through (12). In each case $T_{\text {wall }}$ was set to the temperature recorded by TC1-6. Values of h calculated from samples of the student data differed by less than $36 \%$ of the values determined using equations (8) through (11).

Table 2 Comparison of the analytically and experimentally determined convection heat transfer coefficients.

\begin{tabular}{cccc}
\hline Station & $\mathrm{h}_{\exp }\left(\mathrm{W} / \mathrm{m}^{2}-\mathrm{K}\right)$ & $\mathrm{h}_{\mathrm{an}}\left(\mathrm{W} / \mathrm{m}^{2}-\mathrm{K}\right)$ & $\%$ Diff \\
\hline 1 & 6.0 & 6.6 & $9 \%$ \\
2 & 5.6 & 5.9 & $5 \%$ \\
3 & 4.1 & 5.5 & $25 \%$ \\
4 & 6.8 & 5.2 & $30 \%$ \\
5 & 5.5 & 5.0 & $11 \%$ \\
6 & 3.0 & 4.7 & $36 \%$ \\
\hline
\end{tabular}

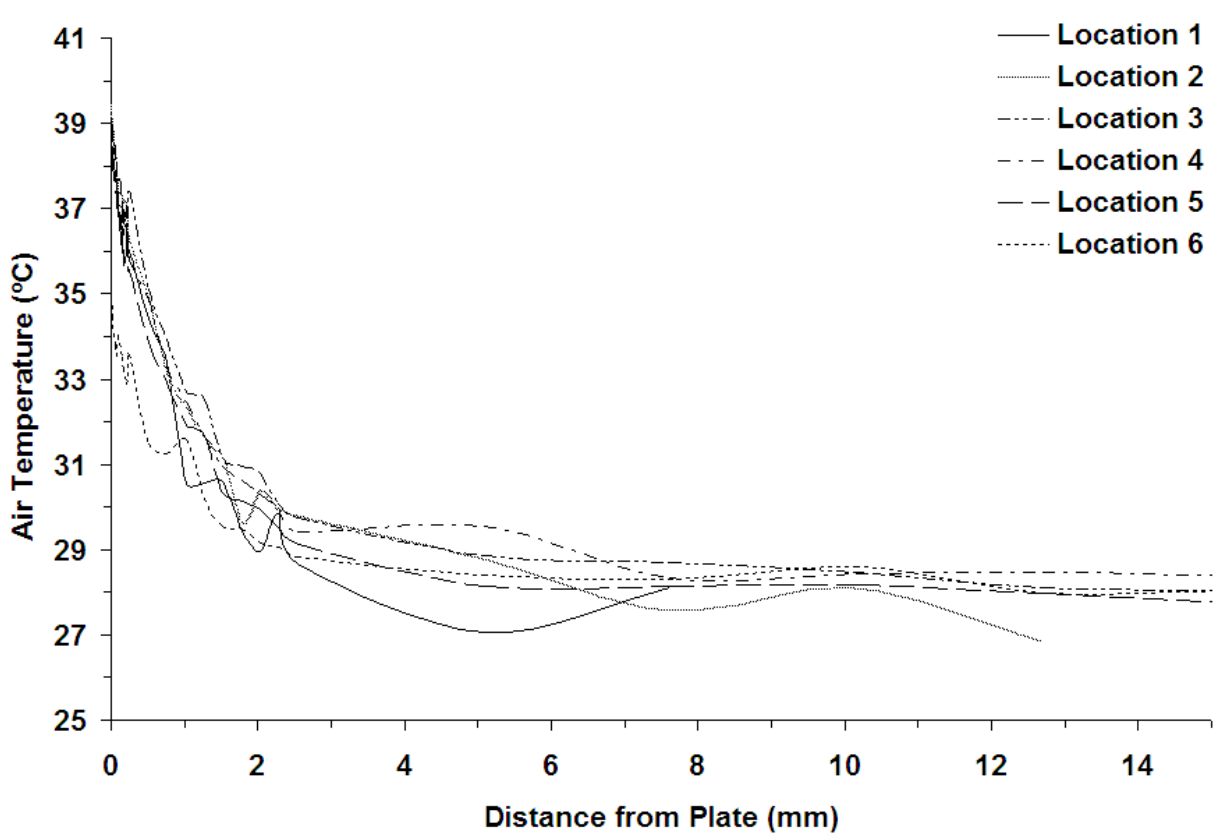

Figure 6 Air temperature measured within the thermal boundary over a heated plate. 


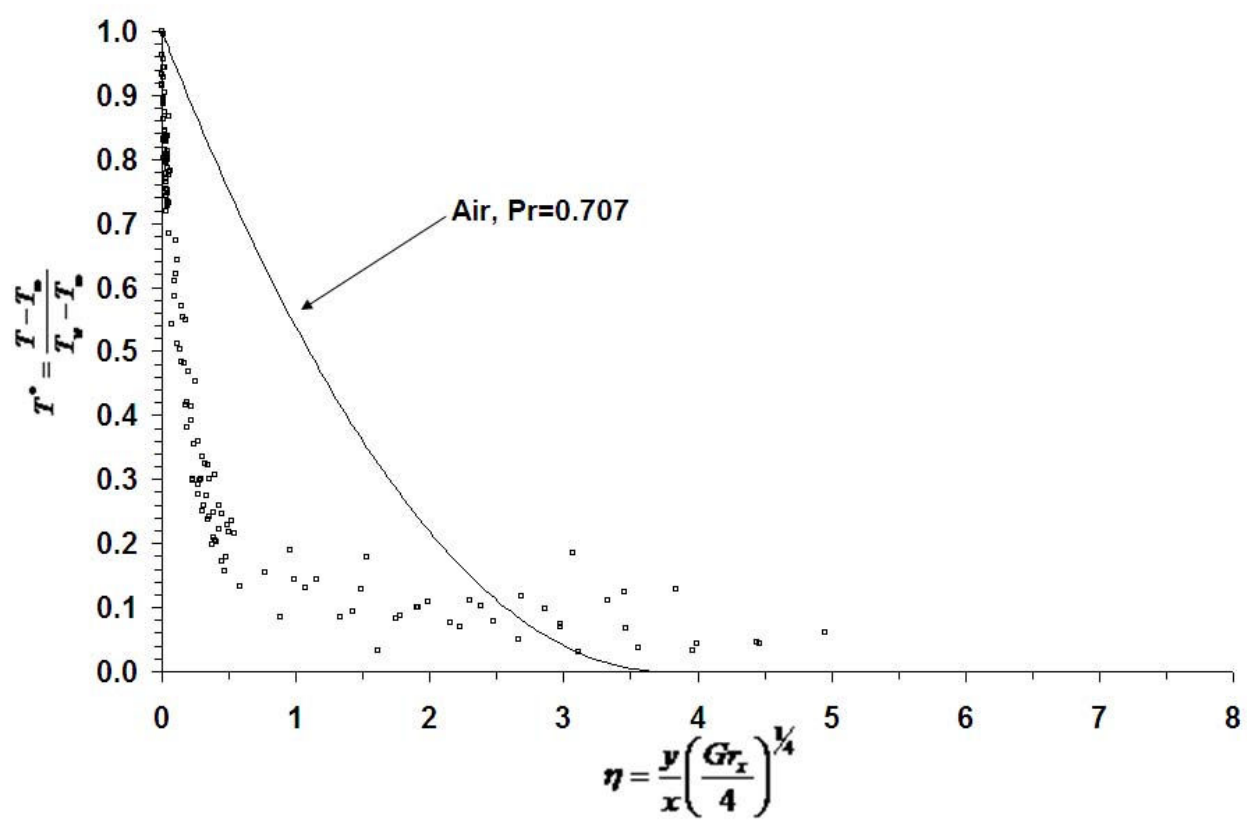

Figure 7 Similarity plot of measured temperature profiles at six locations along the surface of a heated plate compared to the similarity solution of air $(\operatorname{Pr}=0.707)$.

\section{Assessment of Educational Value and Student Feedback}

In MECE 352, students performed a total of 6 experiments--3 in fluid mechanics and 3 in heat transfer/thermodynamics. In order to assess the educational value of the experiments, we required the students to write a lab report and take a quiz (three multiple choice and two true/false questions of equal weight) after the completion of each experiment. The students had one week to complete the lab reports and took the quizzes when they submitted the lab report. They were not allowed to use notes or textbooks during the quiz.

40 out of 41 students submitted a lab report for the lab described in this paper. 8 scored above $90 \%$ and 22 scored above $80 \%$ (Mean grade $=87 \%$ ). All 41 students took the quiz. 9 scored $5 / 5,11$ of the students scored $4 / 5$, and the remainder 21 students scored $3 / 5$ or less. The overall average was $3.5 / 5$, or $70 \%$.

We used the discrepancy between the mean quiz grade and mean lab report grade (quiz grade minus report grade) as an assessment tool to compare the 6 labs taught in MECE 352. As shown above, the discrepancy for the experiment outlined in this paper was $-17 \%$. The mean discrepancy for the 5 previously used experiments was approximately $-8.2 \%$ (S.D. $=5.6 \%$ ). Taking into account the advanced nature of convective heat transfer theory we consider the $-17 \%$ discrepancy to be a sign that with minor modifications this experiment will be a successful educational tool.

Students were asked to complete a survey that assessed their perception of the educational value of the experiment (Appendix A). 23 students completed the survey. Their responses are summarized in Table 3. Overall, the students felt that the experiment enhanced their 
understanding of convective heat transfer theory (statements 1 and 2), that the procedure of the experiment was clear (statement 3 ) and the difficulty reasonable (statement 4).

In addition to a scale ranking the students were also asked to make general comments on the survey. The comments in general indicated that the experiment allowed students to understand the difficulty entailed in experimentation. Some representative comments are provided below.

- "I believe that this lab helped me to understand the difficulty of precise measurement of natural convection. Before doing the experiments I tended to think that ... data acquisition was a much easier process than it actually is."

- "...it was cool to actually see what we saw in the textbook happening in real life. It cemented what we had already learned..."

- "This experiment was a good one and very helpful in understanding the concepts of natural convection..."

Table 3 Results from the Natural Convection Experiment survey (Spring 2007).

\begin{tabular}{|c|c|c|c|c|c|c|c|c|}
\hline \multirow{2}{*}{ Survey Statement } & \multicolumn{7}{|c|}{ Number of Students Surveyed } & \multirow{2}{*}{$\begin{array}{l}\text { Average } \\
\pm \text { S.D. }\end{array}$} \\
\hline & 1 & 2 & 3 & 4 & 5 & 6 & 7 & \\
\hline $\begin{array}{l}\text { 1. The lab experiment helped me understand the } \\
\text { convective heat transfer theory learned in heat } \\
\text { transfer class. }\end{array}$ & - & - & 2 & 4 & 6 & 10 & 1 & $5.2 \pm 3.6$ \\
\hline $\begin{array}{l}\text { 2. The heat transfer experiment gave me a better } \\
\text { understanding of convective heat transfer } \\
\text { correlations and data, their applicability and } \\
\text { limitations. }\end{array}$ & - & - & 2 & 3 & 7 & 9 & 2 & $5.3 \pm 3.2$ \\
\hline 3. The procedure was clear and understandable. & - & - & 1 & 5 & 5 & 10 & 2 & $5.3 \pm 3.5$ \\
\hline $\begin{array}{l}\text { 4. The difficulty level of the experiment was } \\
\text { reasonable. }\end{array}$ & 1 & 1 & 1 & 3 & 8 & 7 & 2 & $5.0 \pm 3.0$ \\
\hline
\end{tabular}

Poor $-1-2-3-4-5-6-7-$ Outstanding

* Survey modeled after Clausen et al ${ }^{[2]}$.

\section{Conclusion}

Contemporary data acquisitions tools are becoming cheaper and easier to use. The classic heat transfer experiment we describe above serves as a prime example. This opens up powerful educational opportunities to teaching-focused engineering departments. Acquainting students with various data acquisition tools prepares them for research and development, the design of control systems, and the testing of prototypes. In addition, it intimately acquaints students with the physics of phenomena in a way that develops their intuition about the behavior of matter. Our assessment of and feedback from students suggest that the experiment described here successfully introduced students to data acquisition techniques in heat transfer and thermal boundary layers. We believe that, in the future, taking additional time at the beginning of the experiment to familiarize students with the fundamentals of thermal boundary layers will enhance their understanding of the phenomenon and thereby the educational value of the experiment. 


\section{Acknowledgements}

The authors would like to thank the Department of Mechanical and Aerospace Engineering at the State University of New York at Buffalo for allowing Grove City College to adopt and modify the experiment. The authors would also like to thank Jim Paich and Patrick Moore for building the experimental apparatus.

\section{Nomenclature}

$\begin{array}{ll}\mathrm{g} & \text { acceleration due to gravity, } \mathrm{m} / \mathrm{s}^{2} \\ \mathrm{Gr}_{\mathrm{x}} & \text { Grashof number at a specific } \mathrm{x} \text { station } \\ \mathrm{h}_{\mathrm{an}} & \text { analytically determined convective heat transfer coefficient, } \mathrm{W} / \mathrm{m}^{2}-\mathrm{K} \\ \mathrm{h}_{\mathrm{exp}} & \text { experimentally determined convective heat transfer coefficient, } \mathrm{W} / \mathrm{m}^{2}-\mathrm{K} \\ \mathrm{h}_{\mathrm{x}} & \text { local convective heat transfer coefficient, } \mathrm{W} / \mathrm{m}^{2}-\mathrm{K} \\ \mathrm{k} & \text { thermal conductivity, W/m-K } \\ \mathrm{k}_{\mathrm{air}} & \text { thermal conductivity of air, W/m-K } \\ \mathrm{NU}_{\mathrm{x}} & \text { local Nusselt number } \\ \overline{N u}_{L} & \text { average Nusslet number at location } \mathrm{L} \\ \mathrm{Pr} & \text { Prandtl number } \\ \mathrm{Ra} & \text { Rayleigh number } \\ \mathrm{Ra} & \text { Rayligh number at location L } \\ \mathrm{T} & \text { fluid temperature, }{ }^{\circ} \mathrm{C} \\ \mathrm{T}_{\infty} & \text { fluid temperature far from the wall, }{ }^{\circ} \mathrm{C} \\ \mathrm{T}_{\mathrm{w}} & \text { wall surface temperature, }{ }^{\circ} \mathrm{C} \\ \mathrm{u} & \mathrm{x} \text { component of the fluid velocity, } \mathrm{m} / \mathrm{s} \\ \mathrm{v} & \text { y component of the fluid velocity, } \mathrm{m} / \mathrm{s} \\ \mathrm{x} & \text { distance along surface of heated plate, in or mm } \\ \mathrm{y} & \text { distance away from heated plate, in or mm } \\ \alpha & \text { thermal diffusivity of the fluid, }{ }^{2} / \mathrm{s} \\ \beta & \text { volumetric thermal expansion coefficient }=1 / \mathrm{T} \text { for an ideal gas, } \mathrm{K}^{-1} \\ \mathrm{v} & \text { kinematic viscosity of the liquid, } \mathrm{m}^{2} / \mathrm{s}\end{array}$




\section{Appendix A}

The following survey is anonymous. Please indicate your responses to each question by circling the appropriate score according to the following scale.

Poor $-1-2-3-4-5-6-7$ - Outstanding

You are also encouraged to make additional comments in the "general comments" section.

\section{Questions:}

1. The lab experiment helped me understand the convective heat transfer theory learned in heat transfer class.

$1-2-3-4-5-6-7$

2. The heat transfer experiment gave me a better understanding of convective heat transfer correlations and data, their applicability and limitations.

$1-2-3-4-5-6-7$

3. The procedure was clear and understandable.

$1-2-3-4-5-6-7$

4. The difficulty level of the experiment was reasonable.

$1-2-3-4-5-6-7$

General Comments:

\section{Bibliography}

1. Abu-Mulaweh, H.I. Portable Experimental Apparatus for Demonstrating Thermodynamic Principles. in American Society for Engineering Education Annual Conference and Exposition. 2002. Montreal, QC.

2. Clausen, E. and W. Penney. Laboratory Demonstrations/Experiments in Free and Forced Convection Heat Transfer. in American Society of Engineering Education Annual Conference \& Exposition. 2006. Chicago, IL.

3. Forsberg, C.h. A Demonstration Unit to Enhance Heat Transfer Lectures on Natural and Forced Convection. in American Society of Engineering Education Annual Conference \& Exposition. 2003. Nashville, TN.

4. Forsberg, C.H. A Heat Transfer Experiment to Illustrate Dimensional Analysis. in American Society of Engineering Education Annual Conference \& Exposition. 2005. Portland, OR.

5. Scott, T.C. and C.H. Mitchell. Versatile, Low Cost Convective Heat Transfer Lab. in American Society of Engineering Education Annual Conference \& Exposition. 2004. Salt Lake City, UT.

6. Smith, A.N. and R.J. Volino. Versatile Heat Transfer Lab for Conducting Bench-Top Experiments. in American Society of Engineering Education Annual Conference \& Exposition. 2005. Portland, OR.

7. Chaote, R. and K. Schmaltz. Design, Build and Test in a Thermal Fluids Laboratory Course. in American Society of Engineering Education Annual Conference \& Exposition. 2005. Portland, OR.

8. Abu-Mulaweh, H.I. Integration a Design of Emperiment in the Heat Transfer Laboratory. in American Society of Engineering Education Annual Conference \& Exposition. 2003. Nashville, TN.

9. Incropera, F.P. and D.P. Dewitt, Fundamentals of Heat and Mass Transfer. 1996: John Wiley \& Sons, Inc. 486.

10. Ostrach, S., An Analysis of Free Convection Flow and Heat Transfer About a Flat Plate Parallel to the Direction of the Generating Body Force. 1953, National Advisory Committee for Aeronautics.

11. Churchhill, S.W. and H.H.S. Chu, Correlating Equations for Laminar and Turbulent Free Convection from a Vertical Plate. International Journal of Heat and Mass Transfer, 1975. 18: p. 1323. 